\title{
DESIGN, PERFORMANCE ANALYSIS OF WING, AND MANUFACTURING OF FIXED WING HAND LAUNCH UNMANNED AERIAL VEHICLE
}

\author{
Krishn Das Patel \\ M.Tech Department of Aeronautical, \\ Veltech Rangarajan Dr. Sagunthala R\&D \\ Institute of Science and Technology, \\ Avadi, Chennai, India
}

\begin{abstract}
This paper concentrates on the design, analysis, and development of fixed-wing hand launch unmanned aerial vehicle (UAV). This flight can able to carry the payloads of 0.8 . The design process involves the conceptual, preliminary, and detailed design. This paper involves the investigation of the aerodynamic characteristics over the wing to enhance the aerodynamic design of the UAV. This analysis includes estimating the best gliding ratio to increase the flight mission and attain the maximum altitude. This simulation will be performed for subsonic flow with Mach number $0.04202(14.3 \mathrm{~m} / \mathrm{s})$. The manufacturing of the $\mathrm{UAV}$ is done using composite materials like glass fiber of both (1mm and $2 \mathrm{~mm}$ ) thickness, carbon fiber of $\mathbf{2 m m}$, and carbon rod is used for connecting the empennage to the fuselage. The detailed design has been done in CATIA V5 and the analysis of the wing has been done using XFLR, ANSYS (fluent).
\end{abstract}

Keywords - Fixed-wing hand launch UAV, Design process, Aerodynamic characteristics, Gliding ratio, Manufacturing, Composite materials, Glass fiber, Carbon fiber, CATIA V5, XFLR, ANSYS (fluent).

\section{INTRODUCTION}

A UAV, a mobile robot, can be controlled from either ground station or flown autonomously with a high-level control algorithm. Many UAVs are designed with different kinds of configurations depending upon their usage. These configuration designs come from the wide range of its missions and objectives they are used for. Nowadays, most of

\author{
Bala Syam Kumar Karuparthi \\ B. Tech, Department of Aeronautical, \\ Veltech Rangarajan Dr. Sagunthala R\&D \\ Institute of Science and Technology, \\ Avadi, Chennai, India
}

the military or defense missions and reconnaissance are done using UAVs [1]. Also, unmanned aerial vehicles are increasing in all aspects. This UAV can provide safety and comfort in all phases that earlier required the presence of a human pilot; from precision agriculture, remote sensing, and environment monitoring [2].

Challenges involved in designing and building the UAV include wing design, stabilizer design, stability, weight reduction, and structural integrity [3]. In the past years, the UAV has enticed the attention of scientists and engineers who are working on their design and development to enhance the autonomy and endurance of UAV. The main disadvantage of this UAV is flight autonomy because these are powered by the battery and those are limited to the missions. They are designing nose and empennage shapes of the tactical UAVs to improve the gliding ratio to enhance its flight time and attaining the maximum altitude [4].

\section{LITERATURE STUDY}

The design of any UAV depends on the tasks it carries out. In the design process, many concepts need to be explored for success. At different wing configurations, the rectangular wing has been selected because it is favorable in stability and low speeds [1].

UAV performance analysis may be conducted to predict the effectiveness of designed aircraft. Criteria of this performance analysis are velocity, stall velocity, required trust, and required power. Stall velocity is important prior to flight testing [6]. 
Table -1 Design parameters of similar UAVs [8]

\begin{tabular}{|l|l|l|l|l|l|l|l|}
\hline & Sunrise I & Sunrise II & $\begin{array}{l}\text { Solar } \\
\text { Solitude }\end{array}$ & Solar Excel & SoLong & Zephyr & $\begin{array}{l}\text { SunSailor } \\
1 / 2\end{array}$ \\
\hline $\begin{array}{l}\text { Weight (in } \\
\mathrm{kg} \text { ) }\end{array}$ & 12.25 & 10.21 & 2 & 0.72 & 12.6 & 50 & 3.6 \\
\hline Endurance & $\begin{array}{l}\text { Maximum } \\
\text { flight time } \\
\text { was 4 hours }\end{array}$ & Unknown & Unknown & $\begin{array}{l}11 \text { hours, } \\
34 \text { minutes, } \\
18 \text { seconds }\end{array}$ & $\begin{array}{l}48 \\
\text { hours, } \\
16 \\
\text { minutes }\end{array}$ & $\begin{array}{l}336 \\
\text { hours, 21 } \\
\text { minutes } \\
\text { (Over 14 } \\
\text { days) }\end{array}$ & Unknown \\
\hline $\begin{array}{l}\text { Wingspan } \\
\text { (in m) }\end{array}$ & 9.75 & 9.75 & 2.7 & 2.1 & 4.75 & 22.5 & 4.2 \\
\hline $\begin{array}{l}\text { Aspect } \\
\text { Ratio }\end{array}$ & 11.4 & 11.4 & 13.3 & 12.8 & 15 & 11.6 & 13.15 \\
\hline
\end{tabular}

The Table 2. Shows the Airfoils used in existing UAVs for wing and tail [6], [9], [10], [11], [12], [13]

Table -2 Airfoils Details

\section{Airfoils Details}

\begin{tabular}{cccc}
$\begin{array}{c}\text { Wing } \\
\text { Airfoil }\end{array}$ & $\begin{array}{c}\text { Type of } \\
\text { Airfoil }\end{array}$ & Tail Airfoil & $\begin{array}{c}\text { Type of } \\
\text { Airfoil }\end{array}$ \\
\hline NACA4412 & cambered & NACA 0008 & symmetrical \\
\hline Selig 1223 & cambered & NACA 0009 & symmetrical \\
\hline SD7032 & cambered & HT12 & symmetrical \\
\hline NACA63412 & cambered & NACA 0007 & symmetrical \\
\hline AG 24 & cambered & & \\
\hline NACA 0015 & symmetrical & & \\
\hline
\end{tabular}

The ideal aerodynamic characteristics are inaccurate and not sufficient for calculating and finalizing the performance parameters. These results can be used to compare with experimental or 3D simulation results.

From the literature, for doing the simulation we require the input parameters. Those are taken from the study of some papers which are shown in the analysis, they should step by step procedure.

The main purpose of this research is to design a UAV to obtain the gliding ratio to enhance its flight time and altitude. This paper includes the coefficients of aerodynamic characteristics like lift coefficient, drag coefficient, and moment coefficient. In the pre-processor step, the four turbulence models are selected for the analysis. These include spalart-allmaras, K-epsilon, K-omega, and Reynolds stress model. In the Reynolds stress model and K-epsilon, the standard wall functions can be utilized with models. The results obtained from this analysis showed that the k-epsilon and Reynolds number model converged better compared to other turbulent models. These are varied against the changing angle of attack and inlet velocity. The lift and drag coefficient with changes in AOA results of NACA 2412 at $20.73 \mathrm{~m} / \mathrm{s}$ [14], [15], [19].

\section{METHODOLOGY FLOW CHART OF THE DESIGN ANALYSIS AND MANUFACTURING PROCESS OF UAV}

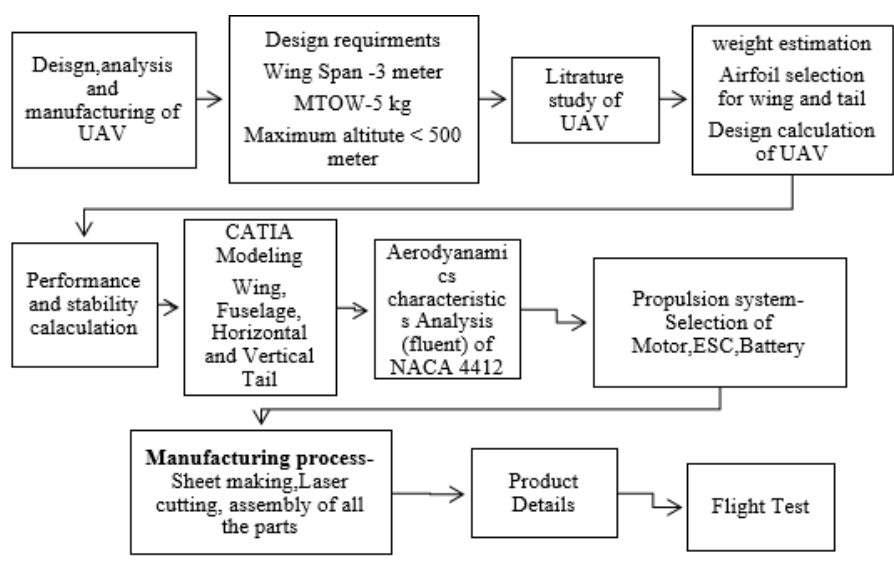

Fig. 1: Flow Chart of Design Analysis and Manufacturing Process of UAV

\section{WEIGHT ESTIMATION}

Generally, the mass components were Divided into the basic elements namely, structure, battery, electronics compotes, control system, and payload shown in equation (1). The combination of the empty weight and payload weight is taken as the take-off weight as shown in equation (2), [6].

$\mathrm{W}_{\text {TOmax }}=\mathrm{W}_{\text {structure }}+\mathrm{W}_{\text {battery }}+\mathrm{W}$ (electric propulsion) $+\mathrm{W}$ (payload) $(1)$

$$
\mathrm{W}_{(\text {TO max })}=\mathrm{W}_{\text {empty }}+\mathrm{W}_{\text {payload }}(2)
$$

Table - 3. Mass Distribution

\begin{tabular}{llll}
\hline \multicolumn{4}{c}{ Mass distribution } \\
\hline Parts & $\begin{array}{l}\text { Calculated } \\
(\mathbf{k g})\end{array}$ & $\begin{array}{l}\text { Measured weight } \\
(\mathbf{k g})\end{array}$ & Error\% \\
\hline $\begin{array}{l}\text { Airframe } \\
\text { weight }\end{array}$ & 2.275 & 2.195 & 3.516 \\
\hline $\begin{array}{l}\text { communication } \\
\text { and control }\end{array}$ & 0.305 & 0.185 & 39.34 \\
\hline propulsion & 1.845 & 1.689 & 8.455 \\
\hline payload & 0.575 & 0.836 & 31.2
\end{tabular}


International Journal of Engineering Applied Sciences and Technology, 2021

Vol. 5, Issue 9, ISSN No. 2455-2143, Pages 233-241

Published Online January 2021 in IJEAST (http://www.ijeast.com)

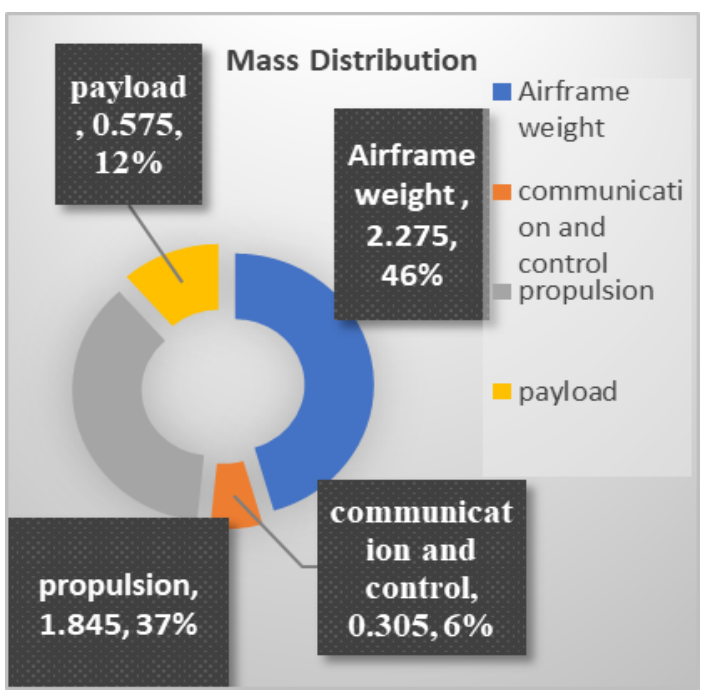

Fig. 2: Mass Distribution

\section{AIRFOIL SELECTION}

The literature and from the existing UAV, few airfoils are selected for the design. Comparing the aerodynamic characters of the listed airfoil, NACA 4412 was chosen among all the airfoils. And for the tail, the airfoil NACA0008 as shown in fig. 3.,4, a symmetrical airfoil, zero lift at zero angles of attack.

Almost all the existing UAV use the symmetric airfoil for providing good pitching moment. The maximum lift coefficient is 1.18 at 12 degrees of a stall.

Table - 4. Aerodynamic Parameters of Wing and Tail

\section{Aerodynamic Characteristics}

\begin{tabular}{ccc}
\hline Variables & Wing & Tail \\
\hline Airfoil & NACA 4412 & NACA0008 \\
\hline Max Lift Coefficient & 1.4 & 1.18 \\
\hline Drag Coefficient & 0.02 & 0.038 \\
\hline Coefficient of Moment & -0.04 & 0.025 \\
\hline Lift to Drag Ratio & 42 & 35 \\
\hline Stall Angle & 15 & 12 \\
\hline
\end{tabular}

To investigate the 2D aerodynamic results of NACA 4412, obtained results from XFLR analysis are shown in figure $5 \&$ 6.

The results of aerodynamic characteristics are obtained at different Reynolds numbers from $0.9 \times 10^{6}$ to $1 \times 10^{5}$.

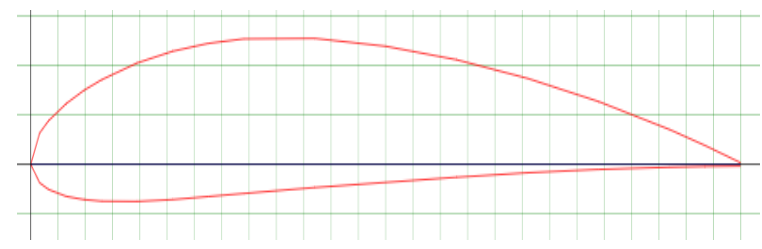

Fig. 3: NACA 4412 Airfoil

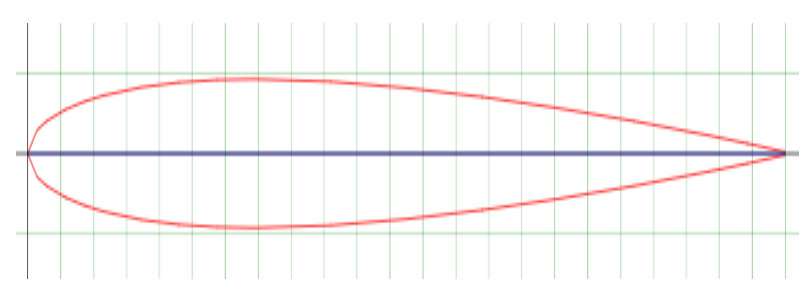

Fig. 4: NACA0008 Airfoil

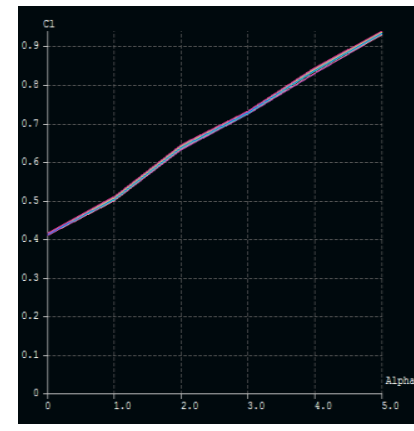

Fig. 5: XFLR analysis graph $\mathrm{Cl}$ Vs Alpha

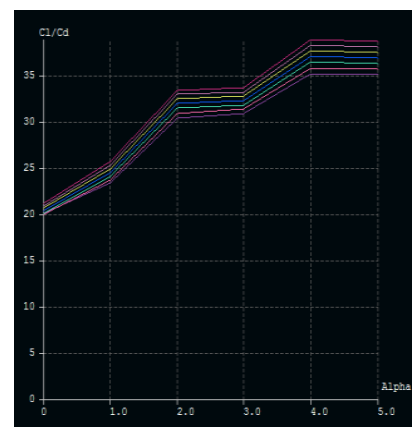

Fig. 6: XFLR analysis graph $\mathrm{Cl} / \mathrm{Cd}$ Vs Alpha
Table No.5 shows the aerodynamic parameters of theoretical, calculated, and XFLR analysis.

Table -5. Values of Gliding Ratio in Three Different Cases

\begin{tabular}{cccc}
\hline Parameters & Theoretical & Calculation & $\begin{array}{c}\text { XFLR } \\
\text { Analysis }\end{array}$ \\
\hline $\begin{array}{c}\text { Lift } \\
\text { coefficient } \\
(\mathrm{Cl})\end{array}$ & 0.5 & 0.55 & 0.5 \\
\hline $\begin{array}{c}\text { Drag } \\
\text { coefficient } \\
(\mathrm{Cd})\end{array}$ & 0.018 & 0.02 & $0.021($ parasite \\
drag)
\end{tabular}

Lift to drag

ratio(L/D) 


\section{DESIGN OF UAV}

A wide variety of unmanned aerial vehicles varying in their shape, size, and configuration have been developed by government/private organizations across the world.

These typically vary in terms of flight speed, operational altitude, and endurance depending on the mission requirements. Historically, UAVs were designed as simple drones, but autonomous control is now increasingly being employed. UAVs come in two varieties: some are controlled from a remote location, and others fly autonomously based on pre-programmed flight paths using more complex dynamic automation systems [20].

\subsection{Dimensions details of UAV}

Table-6 (a), (b) Dimension details of UAV

Table-6. (a)

\begin{tabular}{lc}
\hline \multicolumn{1}{c}{ Main wing } \\
\hline Wingspan & Dimensions \\
\hline Fuselage Length & $1.5 \mathrm{~m}$ \\
\hline Wing Area & $0.782 \mathrm{~m}^{2}$ \\
\hline Wing Chord & $0.26 \mathrm{~m}$ \\
\hline Aileron Area & $0.687 \mathrm{~m}^{2}$ \\
\hline Aileron Length & $0.6 \mathrm{~m}$ \\
\hline Nose Length & $0.3 \mathrm{~m}$ \\
\hline Tail length & $0.6 \mathrm{~m}$ \\
\hline
\end{tabular}

Table 6. (b)

\begin{tabular}{lcc}
\hline \multicolumn{1}{c}{ Parameters } & $\begin{array}{c}\text { Horizontal } \\
\text { Tail } \\
\text { Dimensions }\end{array}$ & $\begin{array}{c}\text { vertical tail } \\
\text { dimensions }\end{array}$ \\
\hline Surface Area & $0.125 \mathrm{~m}^{2}$ & $0.0782 \mathrm{~m}^{2}$ \\
\hline Wing Span & $0.707 \mathrm{~m}$ & $0.274 \mathrm{~m}$ \\
\hline Root Chord & $0.233 \mathrm{~m}$ & $0.228 \mathrm{~m}$ \\
\hline Tip Chord & $0.117 \mathrm{~m}$ & $0.136 \mathrm{~m}$ \\
\hline Control Surface Area & 0.025 & 0.0234 \\
& $\mathrm{~m}^{2}$ (elevator) & $\mathrm{m}^{2}$ (rudder)
\end{tabular}

\subsection{2-D Draft of UAV}
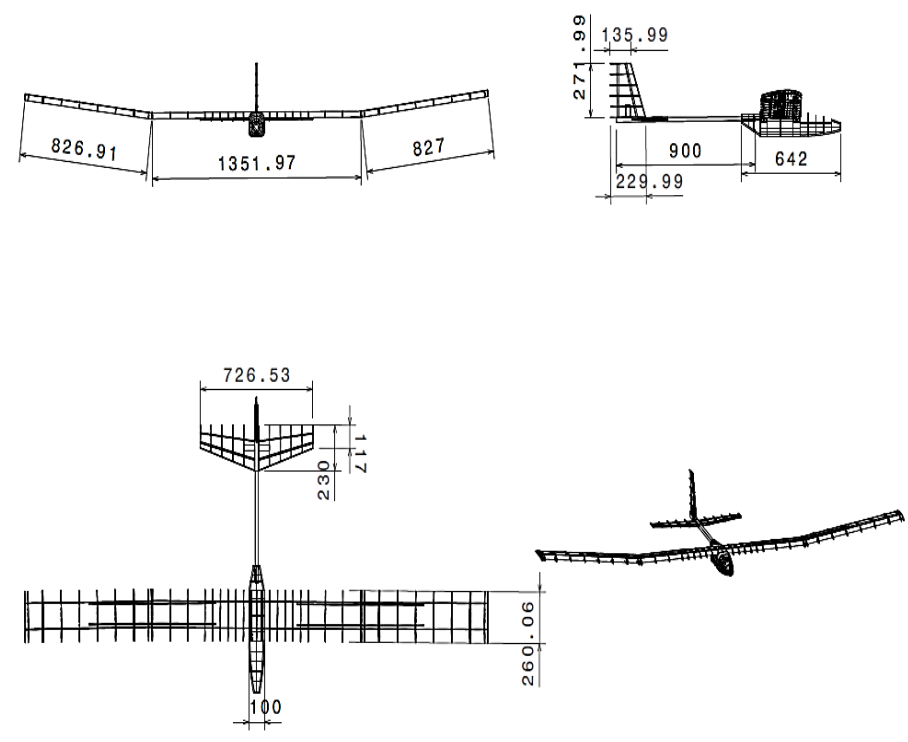

Fig. 7: 2-D View of UAV

\subsection{Performance Calculation}

UAV performance analysis may be conducted to predict the effectiveness of the to-be-designed aircraft. The main performance criteria that are considered are velocity, stall velocity $\left(\mathrm{V}_{\text {Stall }}\right)$, required thrust $\left(\mathrm{T}_{\text {required }}\right),[6]$.

Table -7. Aerodynamic characteristics

\begin{tabular}{|c|c|c|}
\hline \multicolumn{3}{|c|}{ Performance Calculations } \\
\hline Parameters & Formula Used & Values \\
\hline Stall velocity & 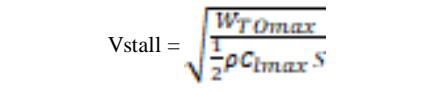 & $8.5 \mathrm{~m} / \mathrm{s}$ \\
\hline cruise velocity & Vcruise $=\sqrt{\frac{W_{\text {Fीprax }}}{\frac{1}{2} \rho C_{1}{ }^{5}}}$ & $14.3 \mathrm{~m} / \mathrm{s}$ \\
\hline lift coefficient & & 1.4 \\
\hline lift & Lift L $=\mathrm{W}=\frac{1}{2} \rho \mathrm{V}_{\text {cruise }}{ }^{2} S C_{\text {limax }}$ & $137.1 \mathrm{~N}$ \\
\hline \multirow[t]{2}{*}{ coefficient } & $\begin{array}{c}C_{\text {dmax }}=C_{\text {dio }}+K C_{i}^{2} \\
\mathrm{~K}=\frac{1}{\text { maRe }}\end{array}$ & 0.0816 \\
\hline & Where $\theta=0.84$ for unswept wing & \\
\hline drag & $\operatorname{Drag} \mathbf{D}=\mathbf{T}=\frac{1}{2} \rho \mathrm{V}_{\text {cruise }}{ }^{2} S C_{\text {dmax }}$ & $8 \mathrm{~N}$ \\
\hline
\end{tabular}




\subsection{CATIA Part Design of UAV}

Using airfoil and related equations, we have a 3-meter wingspan including the dihedral angle of 7 degrees. The following figure shows the design of the wing.
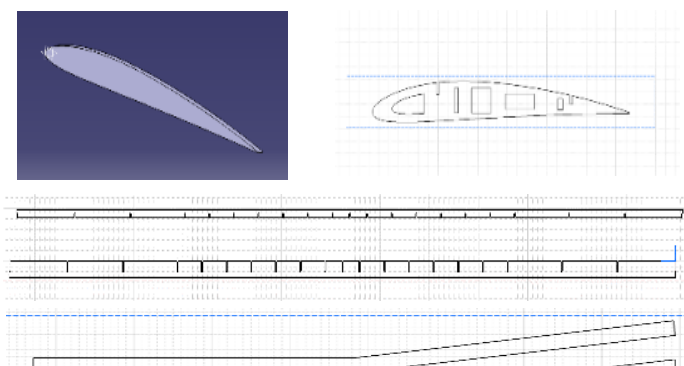

Fig.8: Airfoil, ribs, spars, and dihedral rods

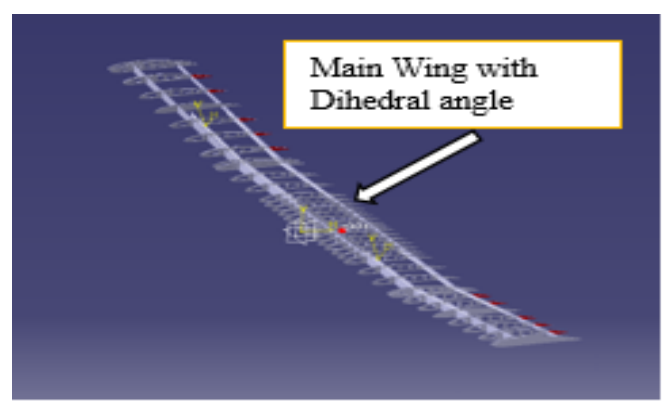

Fig.9: Wing Section

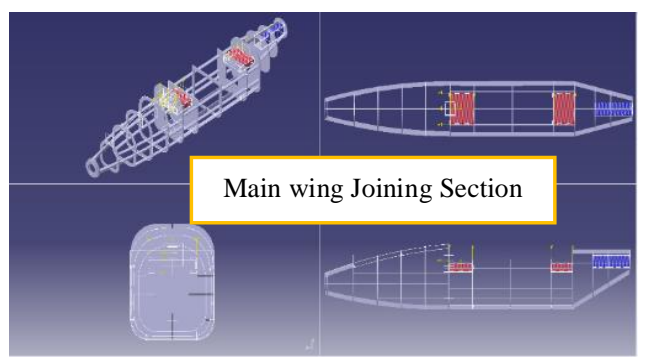

Fig.10: Different Views of Fuselage Section

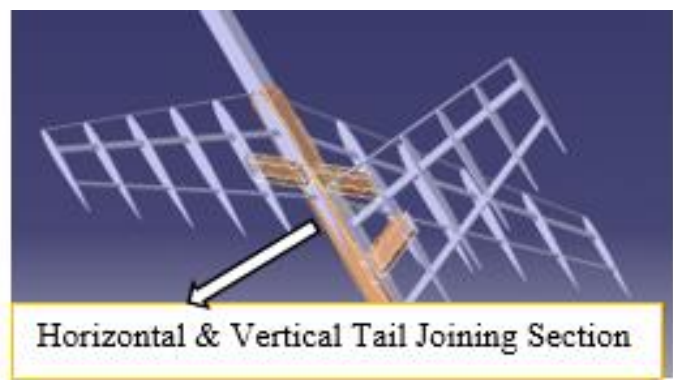

Fig.11: Horizontal and Vertical Tail Section

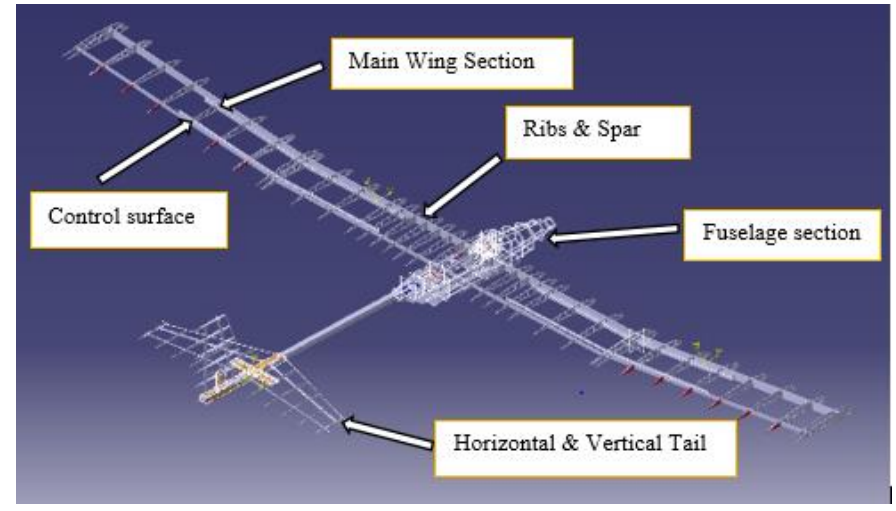

Fig. 12: Finalized Model of UAV

\section{PERFORMANCE ANALYSIS OF WING}

Performance characteristics can be obtained from airflow interacting with objects like a wing, aircraft, etc. due to this interaction, the forces can also be generated. The aerodynamic coefficients like lift, drag, and moment coefficients play an important role in the evaluation of aerodynamic performance.

\subsection{Geometry}

It is a wing of a 1.5-meter wingspan, with 7 degrees of dihedral. Because of its symmetrical condition, half the wing has been taken to investigate the performance analysis, as it reduces time while producing accurate results. The wing should be enclosed with some area or within the body of influence. It is an easier and efficient manner of controlling the mesh sizes for geometries with multiple intersecting closed bodies than using boundary layers. The Boolean operator is the most impactful operation in the analysis. The angle of attack can be changed using body transformations.

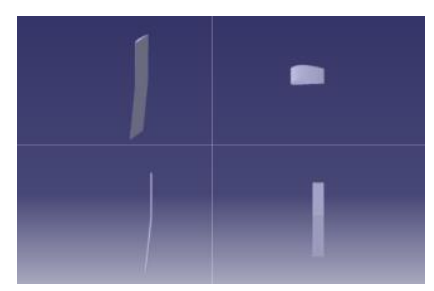

Fig. 13: Wing Geometry

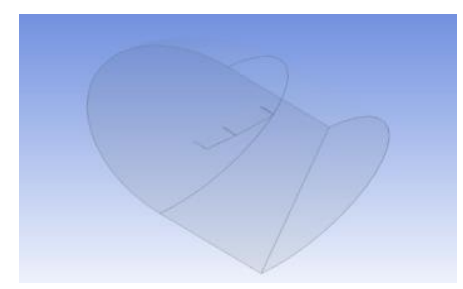

Fig.14:WingGeometry with enclose

\subsection{Meshing}

Mesh creation is the next pre-processing step after the model geometry has been created. The discretization of the fluid flow domain is referred to as the mesh or grid generation. Based on the topology of model geometry. 
International Journal of Engineering Applied Sciences and Technology, 2021

Vol. 5, Issue 9, ISSN No. 2455-2143, Pages 233-241

Published Online January 2021 in IJEAST (http://www.ijeast.com)

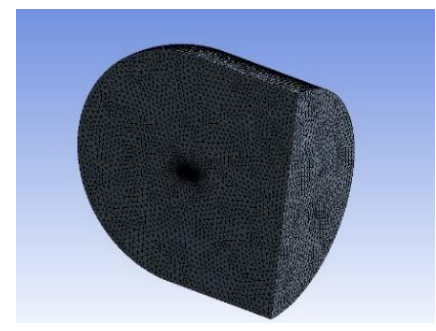

(a)

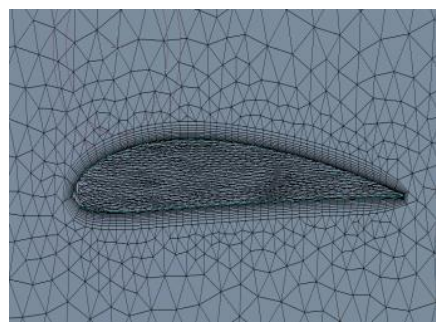

(b)
Figure 15: (a), (b) Mesh creation

The mesh sensitivity is an important part of evaluating the mesh quality in fluent simulations. Different sizing should be created for completing the whole meshing; like body sizing, face sizing, edge sizing to the airfoil. At last, the inflation layers, to get the aerodynamic characteristics with good and accurate results.

\subsection{Fluid parameters and Boundary conditions}

In this pre-processor step, the four turbulence models are selected for the analysis.

These include spalart-allmaras, K-epsilon, K-omega, and Reynolds stress model. In the Reynolds stress model and Kepsilon, the standard wall functions can be utilized with models.

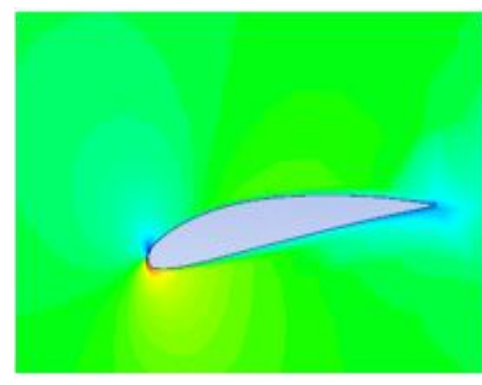

Fig. 16: Velocity contour

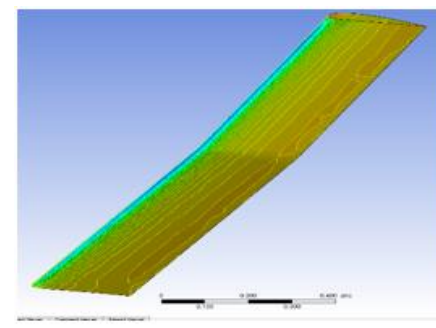

(a)

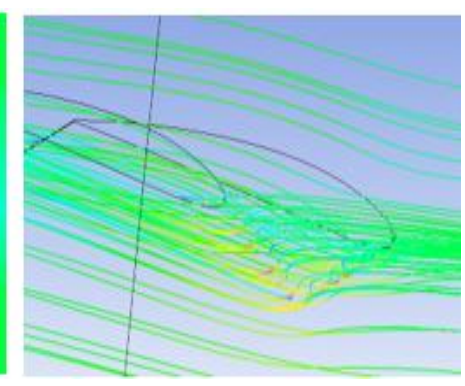

Fig. 17: Streamline

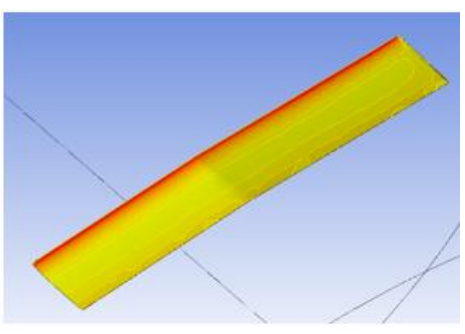

(b)
Fig.18: (a), (b) Pressure contour
Table-8. Initial Parameter

\begin{tabular}{ll}
\hline Parameters & Values \\
\hline Inlet velocity & $14.3 \mathrm{~m} / \mathrm{s}$ \\
\hline Initial temperature & $300 \mathrm{k}$ \\
\hline Initial pressure & $0 \mathrm{psi}$ \\
\hline Turbulence intensity & $5 \%$
\end{tabular}

\subsection{Result}

In the pre-processing, the coefficients of lift, drag, and moment should be initialized with iterations. But these iterations will give the results of lift, drag, and moment coefficients with the same boundary conditions; by changing boundary conditions, angle of attack, and inlet velocity we will get the results over the boundary conditions and aerodynamic characteristics. The results with inlet velocity show the amount of lift and drag that can be produced. The coefficient of lift, drag, and moment can vary with change in the velocity. The other boundary condition is the angle of attack. This may vary the changes in the lift, drag, and moment coefficients. The constant velocity of about $14.3 \mathrm{~m} / \mathrm{s}$ is taken as a boundary condition and the angle of attack is changed.

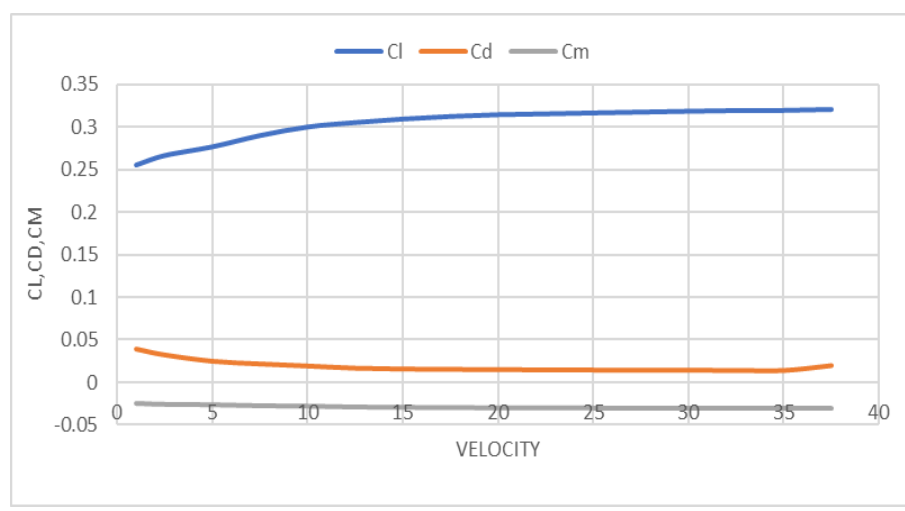

Fig. 19: The graph between $\mathrm{Cl}, \mathrm{cd}, \mathrm{cm}$, and Velocity

The wing efficiency changes with different angles of attack. The main aim of the wing is to generate lift and a high wing efficiency, above $50 \%$ is necessary to improve the unsteady aerodynamic performance. The lift that can be produced from the wing is about $75 \mathrm{~N}$ at 16 degrees of angle of attack which is a stall angle. The UAV can produce maximum lift at 16 degrees. At the same stall angle, drag around $8 \mathrm{~N}$ can be produced. The wing efficiency of a UAV is the ratio of lift coefficient to drag coefficient and it can serve as a basis to determine the aerodynamic performance of a UAV. Also called as gliding ratio is around 20 at 5 degrees of angle of attack 


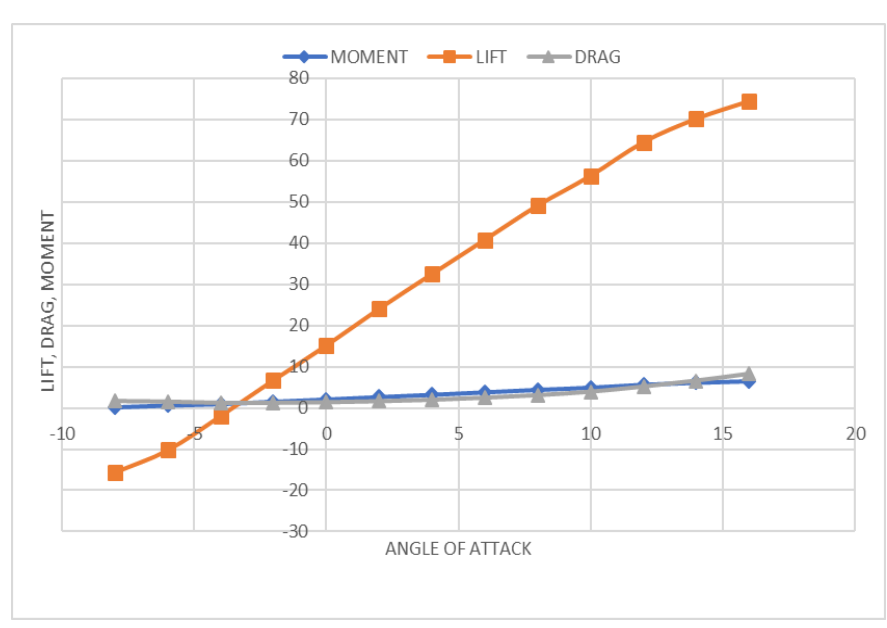

Fig. 20: The graph between lift, drag, moment, and Angle of Attack

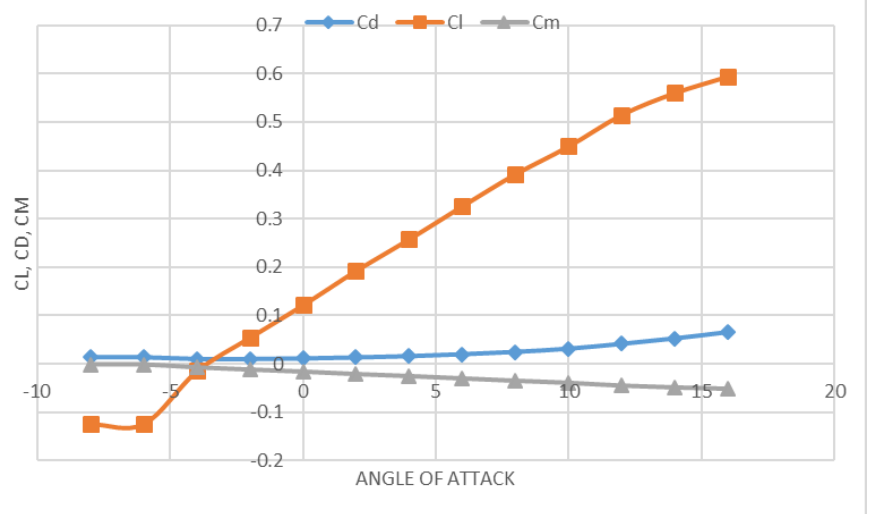

Fig.21: The graph between lift, drag, moment, and Angle of Attack

\section{PROPULSION SYSTEM- SELECTION OF MOTOR, ESC, BATTERY}

Based on the Power requirement for UAV, the electronics components have been selected

Table- 9. List of Electronics

\begin{tabular}{ccc}
\hline $\begin{array}{c}\text { Electronic } \\
\text { Components }\end{array}$ & Quantity & Specification \\
\hline BLDC Motor & 1 & Maximum Power-820w, \\
& & Thrust $-3.212 \mathrm{Kg}$ \\
& & KV rating-900, Maximum \\
& & RMP-8953 \\
& & Peak Current $-57 \mathrm{~A}$ \\
\hline Propeller & 1 & APC $13 * 6.5$ inch \\
\hline ESC & 1 & 80 Amp \\
\hline
\end{tabular}

\begin{tabular}{ccc}
\hline Battery & 1 & $5300 \mathrm{mAh}, 14.8 \mathrm{~V},(4 \mathrm{~s})$ \\
\hline Servo motor & 5 & Rotation-0 to 270 degree \\
\hline
\end{tabular}

\section{UAV MANUFACTURING PROCESS}
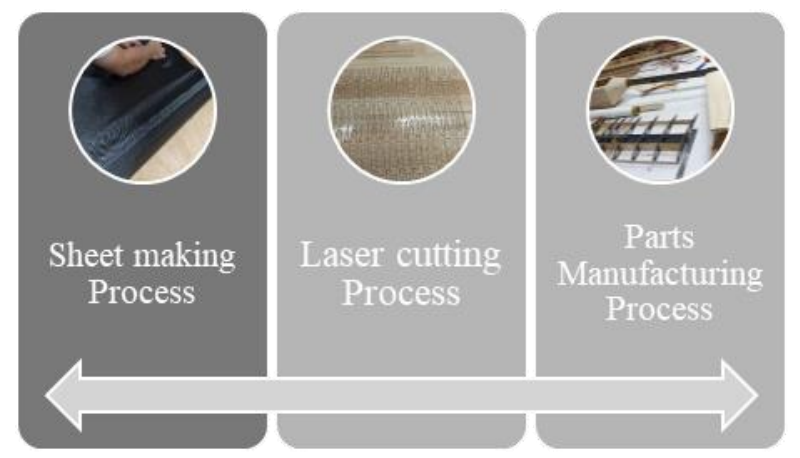

Fig.22: The flow of UAV Manufacturing Process

\subsection{Material details}

For the Wing, Fuselage nose Section, and Tail Section of the UAV parts (Ribs, Spars, Longeron) are made up with the combination of Balsa wood (2- $2.5 \mathrm{~mm}$ thickness sheet) + Carbon fiber sheet +and glass fiber sheet, and nose part of the fuselage and tail section of the UAV is connected with Square carbon fiber rod which is $0.75 \mathrm{~m}$ length and diameter of $4 \mathrm{~cm}$., for the skin we have used $1 \mathrm{~mm}$ and $2 \mathrm{~mm}$ balsa wood sheet. The laser cutting method is used to cut all the parts of the UAV
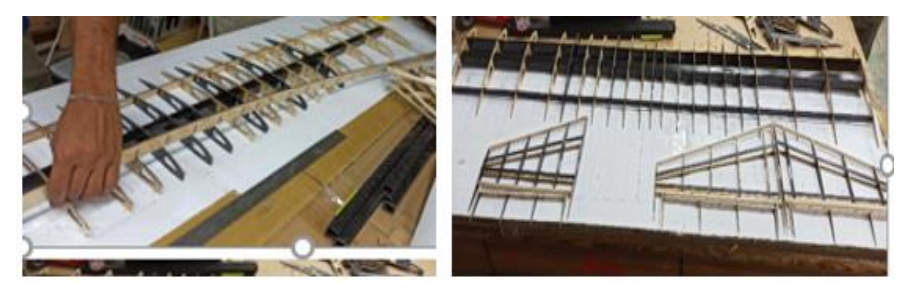

Fig.23: Wing section parts assembly

Fig. 24: Horizontal and Vertical tail parts assembly

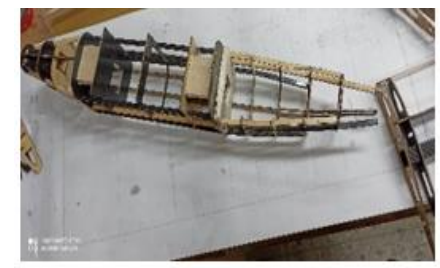

Fig. 25: Fuselage nose section Parts assembly

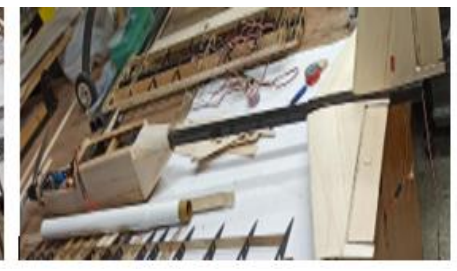

Fig.26 : Fuselage assembly with the tail section 


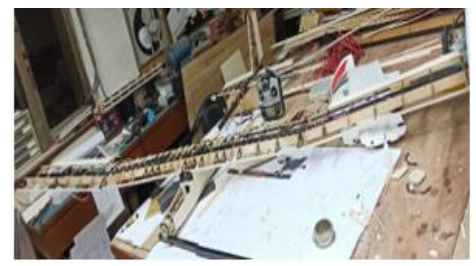

(a)

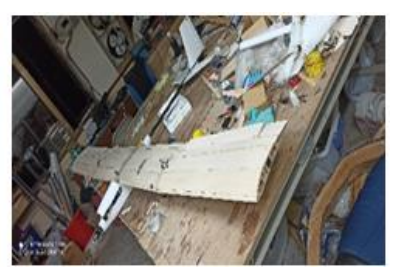

(b)
Fig. 27 (a), (b): Final assembly of parts

\section{PRODUCT DETAILS AND FLIGHT TEST}

\subsection{Product details}

Table -10. Product details

\begin{tabular}{cc}
\hline Parameter & Specification \\
\hline MTOW & $5 \mathrm{Kg}$ \\
\hline Payload Weight & $0.8 \mathrm{Kg}$ \\
\hline Propulsion system & Electric \\
\hline Wing Span & 3 Meter \\
\hline Launching system & Hand launch \\
\hline Maximum Thrust & $3.2 \mathrm{~kg}$ \\
\hline
\end{tabular}

\subsection{Flight test}

The test was performed under very good weather conditions before that ground test have been done like the CG test, Power, Control surface deflection test. there is no autopilot installed inside the UAV, the test flight has performed with manual mode.
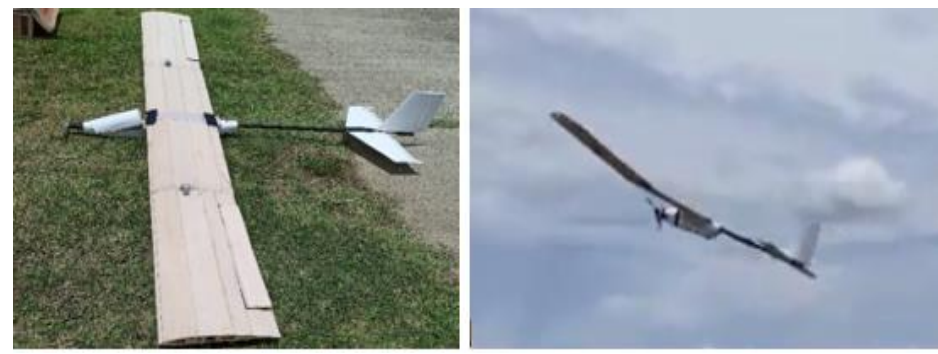

Fig. 28: UAV during ground test

Fig. 29: Aerial view of the UAV

\section{CONCLUSION}

This paper concludes the design and development of UAV and the performance analysis of the wing. From the specifications, it is a LALE UAV with a wingspan of $3 \mathrm{~m}$ and gross weight about $5 \mathrm{~kg}$. This paper substantially enhanced the design and performance characteristics of the expected results. The result is obtained by performing the analysis of the NACA 4412 using ANSYS fluent and XFLR analysis. The investigation includes the validated simulation results of the wing from the literature and to generate the new aerodynamic characteristics at different inlet velocity and angle of attack. Using the Kepsilon turbulence method at a velocity of $14.3 \mathrm{~m} / \mathrm{s}$ and 5 degrees of angle of attack. The lift and drag at the stall angle are around $75 \mathrm{~N}$ and $8 \mathrm{~N}$. Also, the results show no significant effect of free stream velocity on the lift, drag, and moment coefficient.

\section{REFERENCE}

[1] Kaan Taha Oner, (2009), "Modeling and control of a new unmanned aerial vehicle (SUAVİ) with tilt-wing mechanism." ME, Master's Thesis.

[2] Parada, Lu1s Miguel Almodôvar, (2016), "Conceptual and preliminary design of a long endurance electric UAV." $\mathrm{PhD}$ diss., Master's thesis, Instituto Superior Técnico, Universidade de Lisboa.

[3] Khan, s., abdul aabid, and maughal ahmed ali baig,( 2018). "design and fabrication of unmanned aerial vehicle for multimission tasks."International Journal of Mechanical and Production Engineering Research and Development (IJMPERD) ISSN (P): 2249-6890; ISSN (E): 2249-8001 Vol. 8, Issue 4, 475-484

[4] Escobar-Ruiz, Alan G., Omar Lopez-Botello, Luis ReyesOsorio, Patricia Zambrano-Robledo, Luis Amezquita-Brooks, and Octavio Garcia-Salazar, (2019). "Conceptual Design of an Unmanned Fixed-Wing Aerial Vehicle Based on Alternative Energy." International Journal of Aerospace Engineering https://doi.org/10.1155/2019/8104927.

[5] Çetinsoy, Ertuğrul, Efe Sirimoğlu, Kaan Taha Öner, Cevdet Hancer, Mustafa Ünel, Mahmut Faruk Akşit, Ilyas Kandemir, and Kayhan Gülez, (2011). "Design and development of a tilt-wing UAV." Turkish Journal of Electrical Engineering \& Computer Sciences 19, no. 5,733741.

[6] Rajendran, Parvathy, and Howard Smith, (2018), "Development of design methodology for a small solarpowered unmanned aerial vehicle." International Journal of Aerospace Engineering.

[7] André, N. O. T. H., (2008), "Design of solar-powered airplanes for continuous flight." DISS ETH 18010.

[8] Hartney, Christopher J., (2011), Design of a small solarpowered unmanned aerial vehicle. San Jose, CA: San José State University,

[9] Weider, A., H. Levy, I. Regev, L. Ankri, T. Goldenberg, Y. Ehrlich, A. Vladimirsky, Z. Yosef, and M. Cohen, (2006), "Sunsailor: solar powered uav." Technion IIT, Haifa, Israel.

[10] Songqi, Li, Yu Tianning, Wang Xuchhen, and Li Haoran. "The design of a new solar-powered unmanned aircraft."

[11] Dwivedi, Vijay Shankar, Jay Patrikar, Amulya Addamane, and A. K. Ghosh, (2018), "MARAAL: A low 
altitude long endurance solar powered UAV for surveillance and mapping applications." In 2018 23rd International Conference on Methods \& Models in Automation \& Robotics (MMAR), pp. 449-454. IEEE.

[12] Ejeh, Chukwugozie Jekwu, Gbemisola Precious Akhabue, Evans Annan Boah, and Kingsley Kwaah Tandoh, (2019), "Evaluating the influence of unsteady air density to the aerodynamic performance of a fixed-wing aircraft at different angle of attack using computational fluid dynamics." Results in Engineering 4,100037.

[13] Ives, Rob, Edet Bassey, And Faik A. Hamad, (2018), "Investigation of The Flow Around an Aircraft Wing of Section Naca 2412 Utilising Ansys Fluent." Incas Bulletin 10, No. 1.

[14] Schiavetta, Lucy, Okko Boelens, and Willy Fritz, (2006), "Analysis of transonic flow on a slender delta wing using CFD." In 24th AIAA Applied Aerodynamics Conference, p. 3171.

[15] Shinde, Subhash, Akshoy Ranjan Paul, and Anuj Jain, (2013), "CFD analysis of viscous flow over delta-rectangular wing." In 2013 Students Conference on Engineering and Systems (SCES), pp. 1-6. IEEE.

[16] Oettershagen, Philipp, Amir Melzer, Thomas Mantel, Konrad Rudin, Thomas Stastny, Bartosz Wawrzacz, Timo Hinzmann, Kostas Alexis, and Roland Siegwart, (2016), "Perpetual flight with a small solar-powered UAV: Flight results, performance analysis and model validation." In 2016 IEEE Aerospace Conference, pp. 1-8. IEEE.

[17] Ahmed, Tousif, Md Tanjin Amin, SM Rafiul Islam, and Shabbir Ahmed, (2014), "Computational study of flow around a NACA 0012 wing flapped at different flap angles with varying Mach numbers." Global Journal of Research in Engineering.

[18] Karel Lammers, (2015),"Aerodynamic CFD analysis on an experimental airplane." Mechanical Engineering 'Fluid Dynamics, University of Twente \& RMIT University.

[19] Furman, Andrej, and Christian Breitsamter, (2013), "Turbulent and unsteady flow characteristics of delta wing vortex systems." Aerospace Science and Technology 24, no. 1 ,32-44.

[20] Hemant Sharma, C. S. Suraj, Roshan Antony, G. Ramesh, Sajeer Ahmed and Prasobh Narayan, (2013), Design of a High-Altitude Fixed Wing Mini UAV - Aerodynamic Challenges ICIUS-129.

[21] Raymer, Daniel P. Aircraft design: a conceptual approach/Daniel P. Raymer. p. cm.- (AIAA education series).

[22] E.G. Tulapurkara, A. Venkattraman, V.Ganesh, An Example of Airplane Preliminary Design Procedure - Jet Transport. 